\title{
Study of the control algorithm of the braking system of an autonomous haul truck braking system with the use of imitational models
}

\author{
Dmitry Dubinkin ${ }^{1}$, Alexander Kartashov ${ }^{2 *}$, Alexander Muraviev ${ }^{2}$, Nikolai Buzunov $^{2}$, and \\ Ilya Khlobystov ${ }^{2}$ \\ ${ }^{1}$ T.F. Gorbachev Kuzbass State Technical University, Department of Metal Cutting Machines and \\ Tools, 650000 Kemerovo, 28 Vesennyaya st., Russian Federation \\ ${ }^{2}$ Bauman Moscow State Technical University, Wheeled Machines Department, 105005 Moscow, \\ 5 2nd Baumanskaya st., Russian Federation
}

\begin{abstract}
The paper considers different ways of controlling the braking systems of haul trucks. The general approaches used in the development of control systems for such braking systems are described. Methods of testing and imitational mathematical models, used for the analysis of brake system control systems operation, are presented. The developed control system and the imitational model allow us to analyze the brake system behavior under different operating modes of a haul truck.
\end{abstract}

\section{Introduction}

Development of modern automobile industry is aimed at reducing vehicle emissions, due to which there is an increase in the share of electric-powered vehicles [1]. This trend significantly expands the possibilities of braking systems through the use of regenerative braking, but at the same time with these opportunities there is a problem of reliability and safety of these braking systems [5-6], especially for autonomous haul trucks [7-13, 18-20].

This research considers the joint operation of the hydraulic braking system together with the regenerative braking system on quarry haul trucks. The main idea is to assess the possibility of replacing the braking resistors with an electric energy storage device, which will allow to use the accumulated energy on descents for further movement uphill instead of dissipation of energy into heat. In such a scheme it is necessary to implement the possibility of joint operation of the two braking systems to avoid overcharge of the traction battery and to ensure safe braking in case of failure. For this purpose, the hydraulic braking system is supplemented with the possibility of remote braking, which also makes it possible to realize movement in autonomous mode or by means of remote control during the movement of the haul truck on difficult plots.

\footnotetext{
* Corresponding author: kartashov@bmstu.ru
} 


\section{General description of the brake system of the haul truck}

For the studied vehicle, a combined braking system was selected: hydraulic, remotely controlled and electric regenerative system.

The hydraulic brake system includes four circuits: two service brake system circuits, front and rear, a parking brake system circuit and a remote control circuit. Two pedals are provided for operation, one for regenerative braking and the other for the hydraulic brake system. The remote control circuit communicates with the hydraulic brake system pedal.

\section{General description of the algorithm for controlling the elements of the braking system}

The algorithm for the operation of the braking system has three main modes of operation and one auxiliary mode (Fig. 1). The auxiliary mode, called initialization (Initial in Fig. 1), is used for the initial energization of the hydraulic circuits of the brake system after a long stop of the haul truck. The need to use this auxiliary mode is caused by the peculiarities of the architecture of the overall control system of the upper level. In this mode all systems that ensure the movement of the vehicle for safety reasons are blocked.

After initialization, the system operates in one of three possible states. In the parking mode (parkingMode in Fig. 1), the haul truck is immobilized, or stops if the brakes have been activated while driving at a low speed. In this state, first of all, control of actuators of parking brake system is carried out, and also monitoring of a current condition of all systems of a vehicle is carried out. In the event of a malfunction while driving, after stopping there may be a prohibition of further movement and the vehicle will remain immobilized until the failure will be eliminated. In case the braking system is activated while driving at high speed, the transition to the parking mode will be carried out as soon as the minimum speed for brake activation is reached, and until that moment the braking will be carried out by the mechanisms of the working braking system. The operating or normal mode of the system (operatingMode in Fig. 1) controls the actuators of the operating brake system mechanisms. In the case when the haul truck is controlled by the driver, only the auxiliary elements that maintain the operating state of the system work.

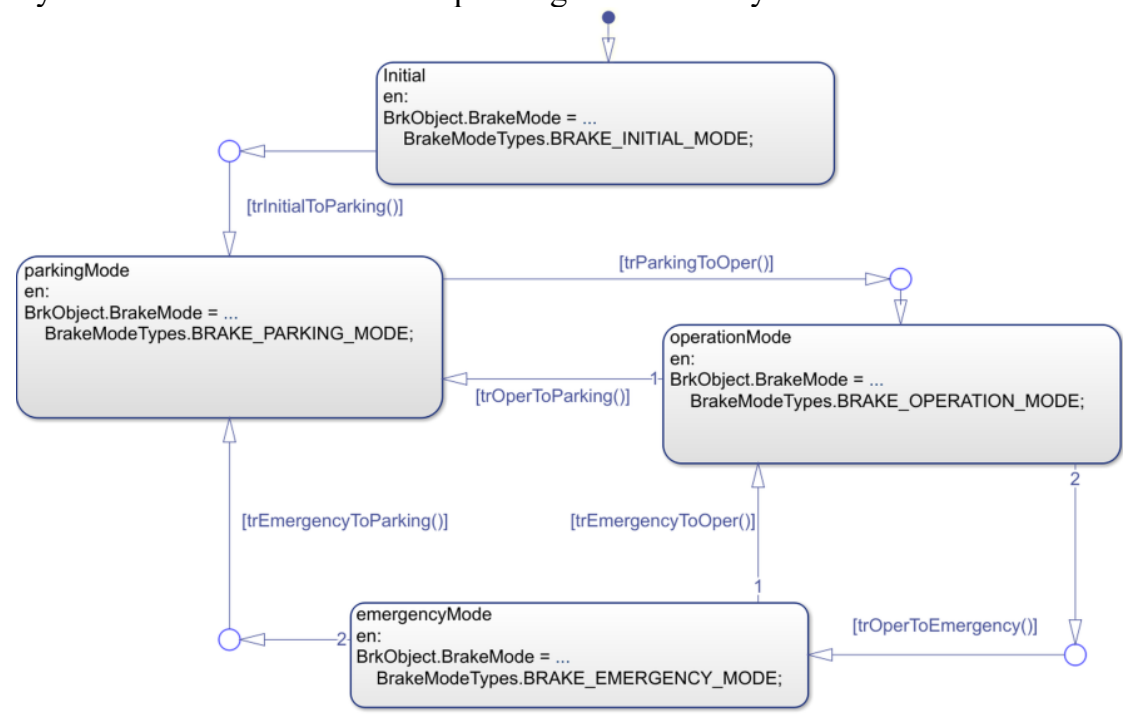

Fig. 1. State machine of the braking system control algorithm 
For the case of autonomous driving, control of haul truck is carried out according to a certain principle, which allows to predict the work of the power equipment and braking system. This feature makes it possible to activate the regenerative braking system in addition to the hydraulic braking system and to vary the proportion of their activation under different road conditions. The regenerative activation fraction depends on many factors, but the main one is to maintain an optimal charge level [2-4], which provides sufficient traction in all modes and a sufficient reserve for energy storage. Depending on the load and driving mode, the control system also adjusts the operation of the regeneration system, but within a narrow range to avoid abnormal situations related to the powertrain operation.

Emergency mode of brake system operation is used for various abnormal situations. The main task of this mode is to protect the elements of the power unit and brakes in case of incorrect actions of the driver or control system errors in the forecasting of the dump truck systems operation. The system switches to the emergency state when there is a risk of traction battery overcharge on a long downhill or in case of activation of the parking brake system at high speed. The system can also activate this mode in the case of a malfunction in any system of the dump truck, which can lead to an accident and harm the health of the driver or if the malfunction could lead to total failure of individual parts or the entire vehicle. It is worth noting that the possibility of overcharge of traction batteries in the pilot control mode, the system will predict in advance and notify the driver about it and only in case of ignoring the warning will implement interception of braking by the hydraulic system. This interception is carried out with a gradual reduction of the share of recuperation engagement, which allows you to keep the vehicle deceleration at the same level. If a critical fault occurs or the parking brake is activated at high speed, the system brakes the vehicle with the service brake system mechanisms.

\section{Model for the evaluation of the brake control algorithm}

The simulation model to evaluate the performance of the brake control algorithm, implemented in the software "MATLAB Simulink", consists of four parts (Fig. 2): the driver imitation module, the brake system control algorithm and the module for calculating the dynamics of the vehicle, which includes the hydraulic part and the mechanical part.
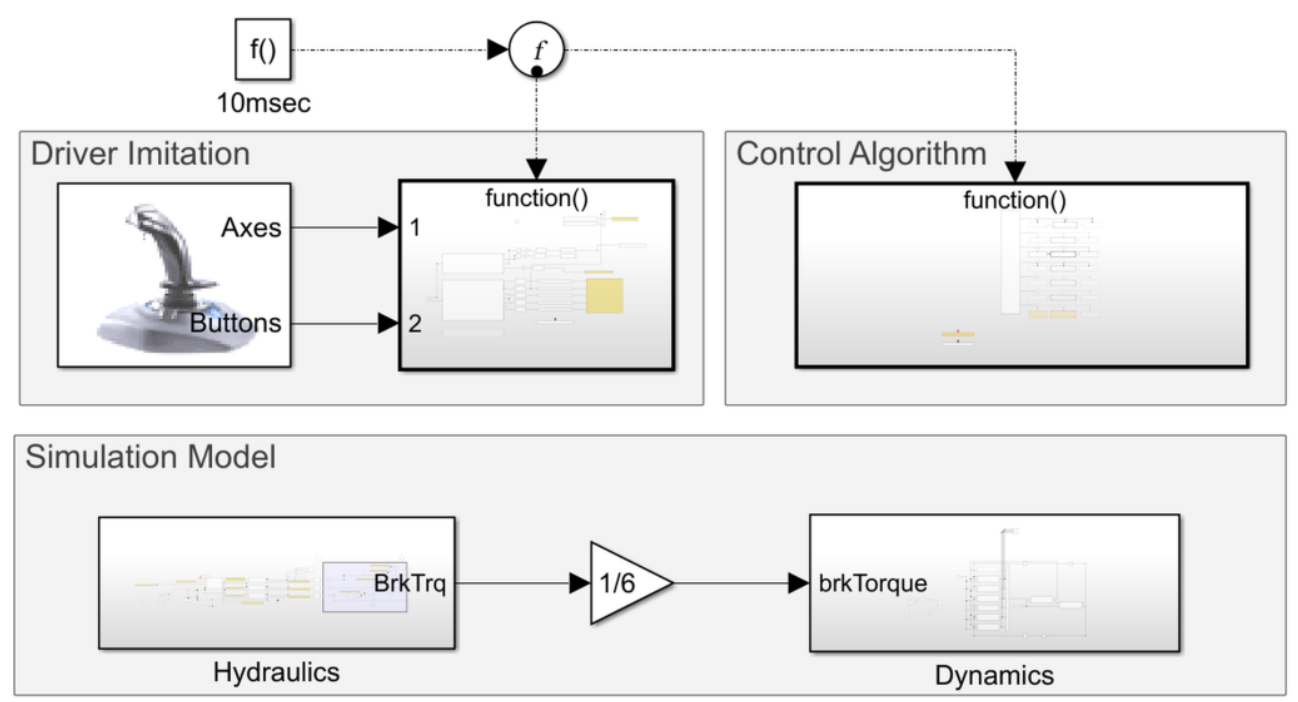

Fig. 2. Imitational model structure 
In the driver imitation module, initial conditions and control actions are set to imitate the actions of the driver or the autonomous driving controller, as well as the states of the other haul truck systems, for example, to set the battery charge level or activate diagnostic restrictions. The control algorithm module includes subsystems for processing input signals, a state machine, functions for controlling circuits of the brake system, functions for transition between states, as well as a function for preparing output signals.

The hydraulic part of the model (Fig. 3) simulates the operation of the main brake circuits of the haul truck and actuators, depending on the pedal pressure or the share of the hydraulic brake system in the case of autonomous driving. Similar to the real brake system, in the model the hydraulic circuits are divided into front, rear, parking and remote, which performs control in emergency situations or autonomous driving [17]. The result of the hydraulic part of the model is the braking torque, which is used to calculate the dynamics of the vehicle in the mechanical part of the model.

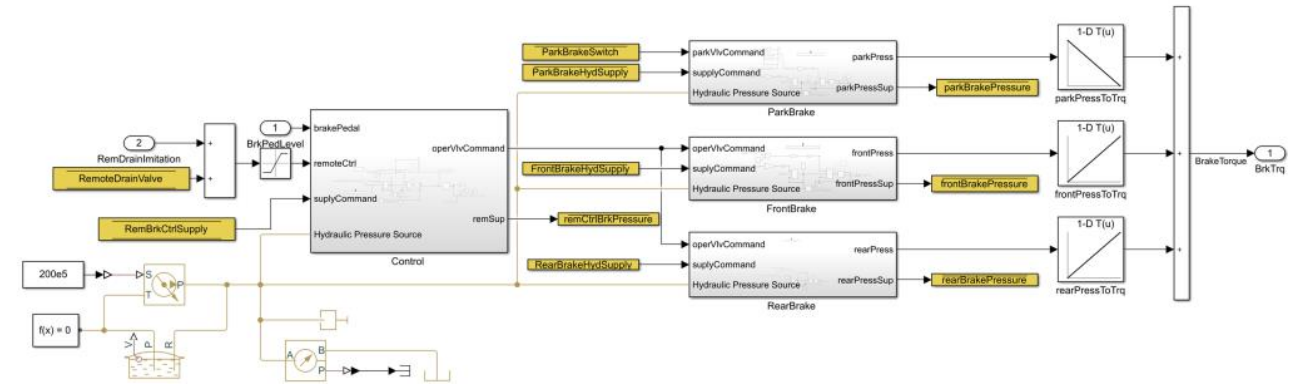

Fig. 3. Structure of the hydraulic part of the mathematical model of the braking system

The part of the model responsible for vehicle dynamics (Fig. 4) is based on differential equations [14-16]. It includes subsystems for calculating wheel dynamics and vehicle body dynamics, where redistribution of reactions during braking is also taken into account. During the analysis, a straight-line motion over a single type of supporting surface without imitation of bumps is evaluated, since it is this scenario of motion that is of most interest in terms of the operability of the algorithm.

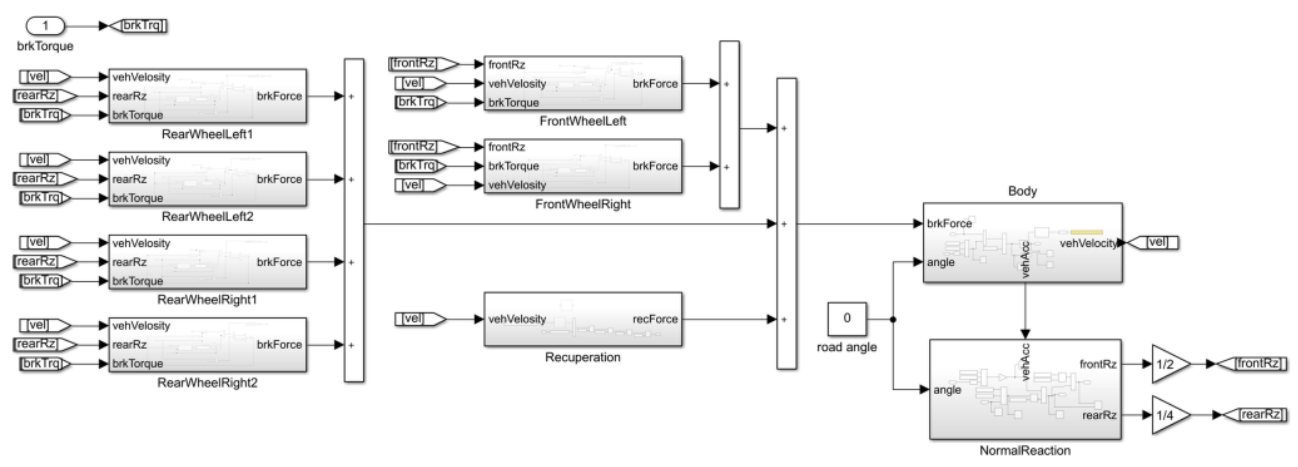

Fig. 4. Structure of the mathematical model of vehicle dynamics

The following system of differential equations is used in modeling:

$$
\left\{\begin{array}{c}
m \dot{v}=2 R_{x f r o n t}+4 R_{x r e a r}-P_{w}, \\
J_{\mathrm{K}} \omega_{w f}^{*}=-M_{f 1}-R_{x 1} \cdot r_{d}, \\
J_{\mathrm{K}} \omega_{w r 1}^{*}=-M_{f 1}-R_{x 1} \cdot r_{d},
\end{array}\right.
$$


where $v$ is linear speed of the wheeled machine, $\mathrm{m} / \mathrm{s} ; m$ - mass of the wheeled machine, $\mathrm{kg}$; $\omega_{w f}-$ angular speed of the wheel of the front axis, $\mathrm{rad} / \mathrm{s} ; \omega_{w r i}-$ angular speed of the wheel of the rear $i$-th axis $(i=1,2), \mathrm{rad} / \mathrm{s} ; r_{d}-$ dynamic radius of the wheel, $\mathrm{m} ; L_{\mathrm{x}}=m_{\mathrm{k}} \cdot r_{d}^{2} / \mathrm{w}^{2}$ - moment of inertia of the wheel, $\mathrm{kg} \cdot \mathrm{m}^{2}$ (where $m_{k}-$ mass of the wheel, $\mathrm{kg} ; P_{w}-$ aerodynamic drag force, $\mathrm{N}$ ).

Vertical reactions are found from the system of equations made on the basis of equality to zero of the sum of moments relative to the points of application of these forces and the sum of the projections of the forces on the vertical axis:

$$
\left\{\begin{array}{c}
2 R_{z 1} \cdot\left(L+l_{r}\right)+4 R_{z 2} \cdot l_{r}+P_{w} \cdot H_{w}+\sum M_{f i}+m \dot{v} \cdot H_{c}=m g \cdot\left(l_{c}+l_{r}\right), \\
2 R_{z 1} \cdot\left(L+l_{r}\right)+P_{w} \cdot H_{w}+M_{f 1}+M_{f 2}+m \dot{v} \cdot H_{c}=m g \cdot\left(l_{c}+l_{r}\right)+4 R_{z 3} \cdot l_{r}+M_{f 3}, \\
2 R_{z 1}+2 R_{z 2}+2 R_{z 3}=m g,
\end{array}\right.
$$

where $H_{c}$ - distance from the supporting surface to the center of mass, $\mathrm{m} ; H_{w}$ - distance from the supporting surface to the center of sail, $\mathrm{m} ; L-$ wheel base of the vehicle, $\mathrm{m} ; L_{c}-$ distance from the point of force application $R_{z}$ to the vehicle center of mass in projection on the horizontal axis, $\mathrm{m} ; M_{k i}$ - torque applied to the wheel on the drive axis, $\mathrm{N} \cdot \mathrm{m}$.

\section{Simulation results and evaluation of the performance of the algorithm}

To verify the performance of the control algorithm, situations during normal operation of the system were simulated, which showed that the braking system meets the technical requirements. Also, studies of the algorithm in abnormal situations for the cases of overcharging of traction batteries and activation of the parking brake at high speed were made.

Figure 5 (blue line) shows a graph of the change in the position of the regenerative pedal. If the driver ignores the battery overcharge notification, the control system sets a flag for the braking system to alert the driver to a possible emergency situation (dashed line in Figure 6). After its activation, the force of the regeneration system is gradually removed and the hydraulic braking system is activated, which is reflected in the graph (Fig. 6). The position of the remote system release valve (red line in Fig. 5) corresponds to the position of the regenerative pedal.

Figure 7 shows the change in wheeled vehicle speed from $40 \mathrm{~km} / \mathrm{h}$ to 0 , with the two brake systems working together. Braking force interception was accomplished in less than 1 second. It can be seen from the graph that full braking was accomplished in 2.5 seconds.

The simulation of the situation with the parking brake activation at high speed is shown in Fig. 8. 


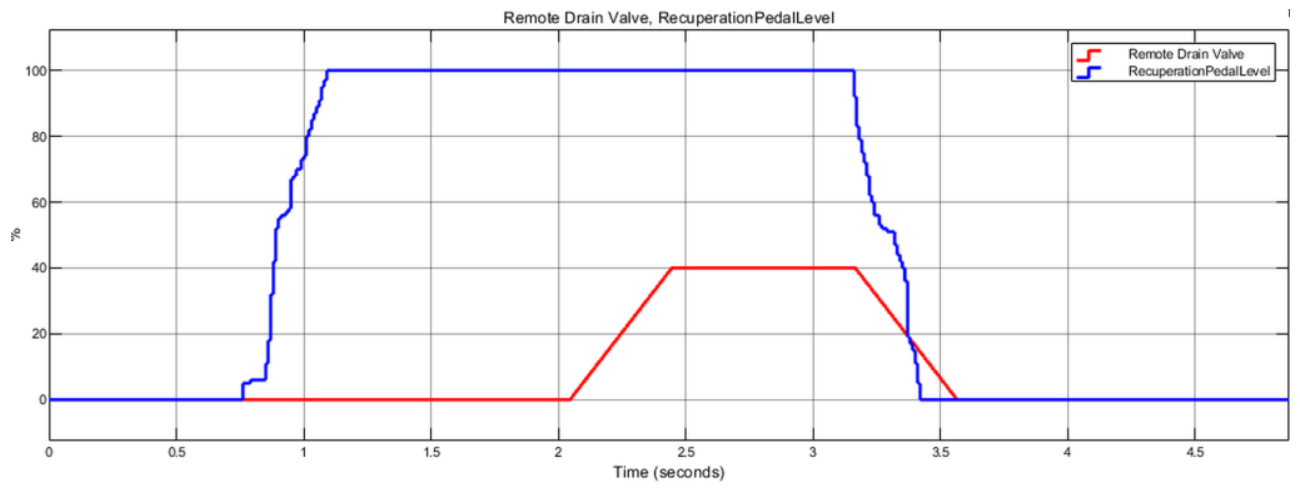

Fig. 5. Positions of the recuperation pedal and remote circuit release valve

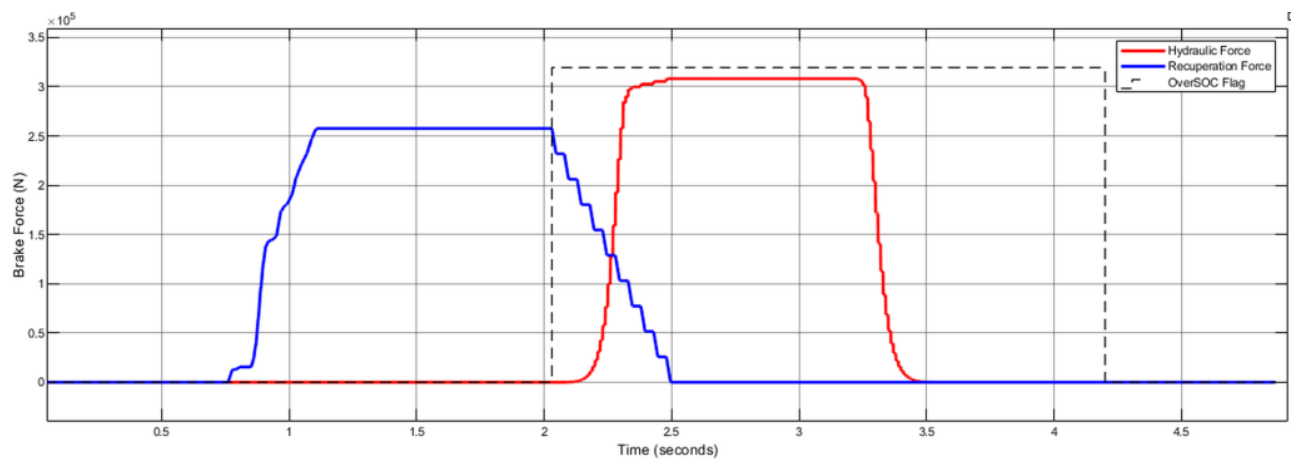

Fig. 6. Interception of hydraulic brake system control during regenerative driving

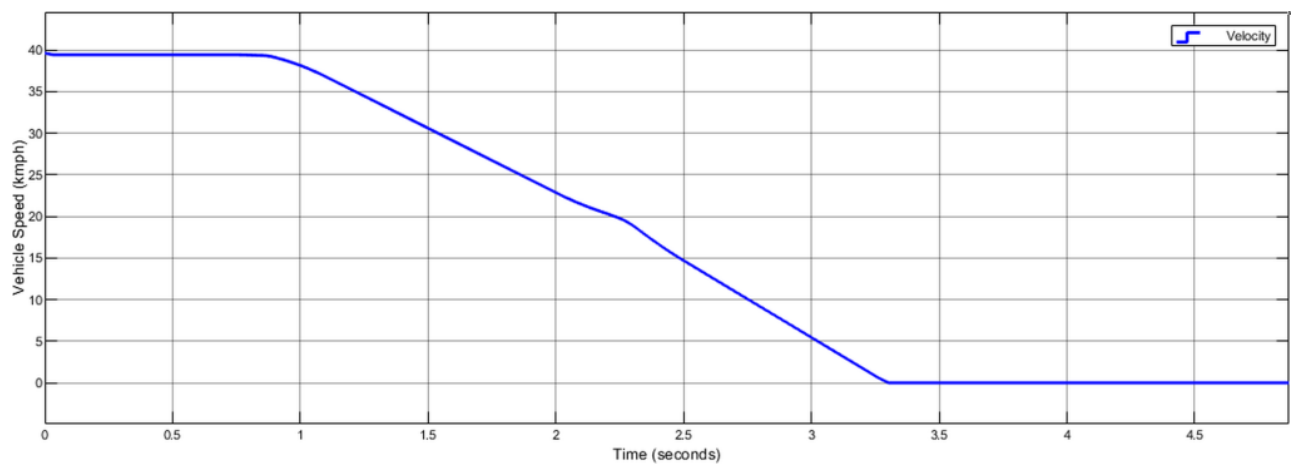

Fig. 7. Diagram of speed change of the wheeled machine

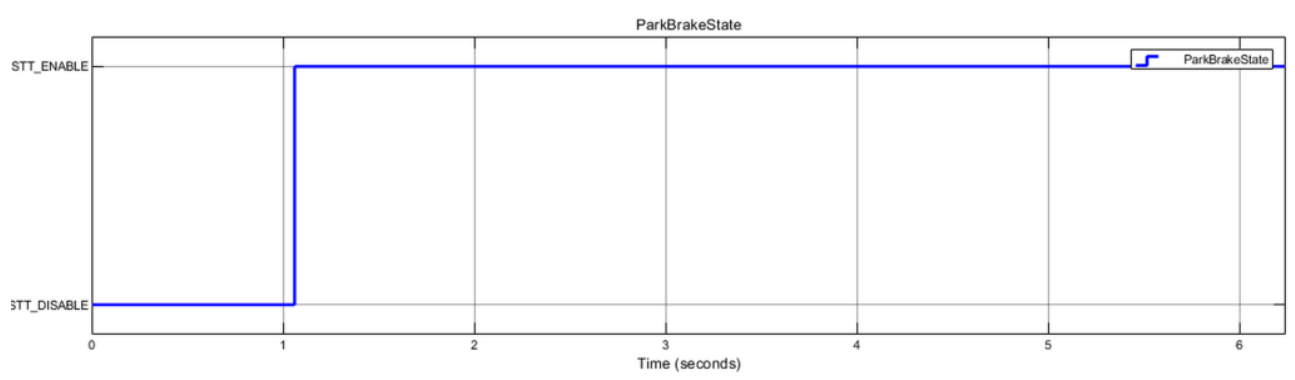



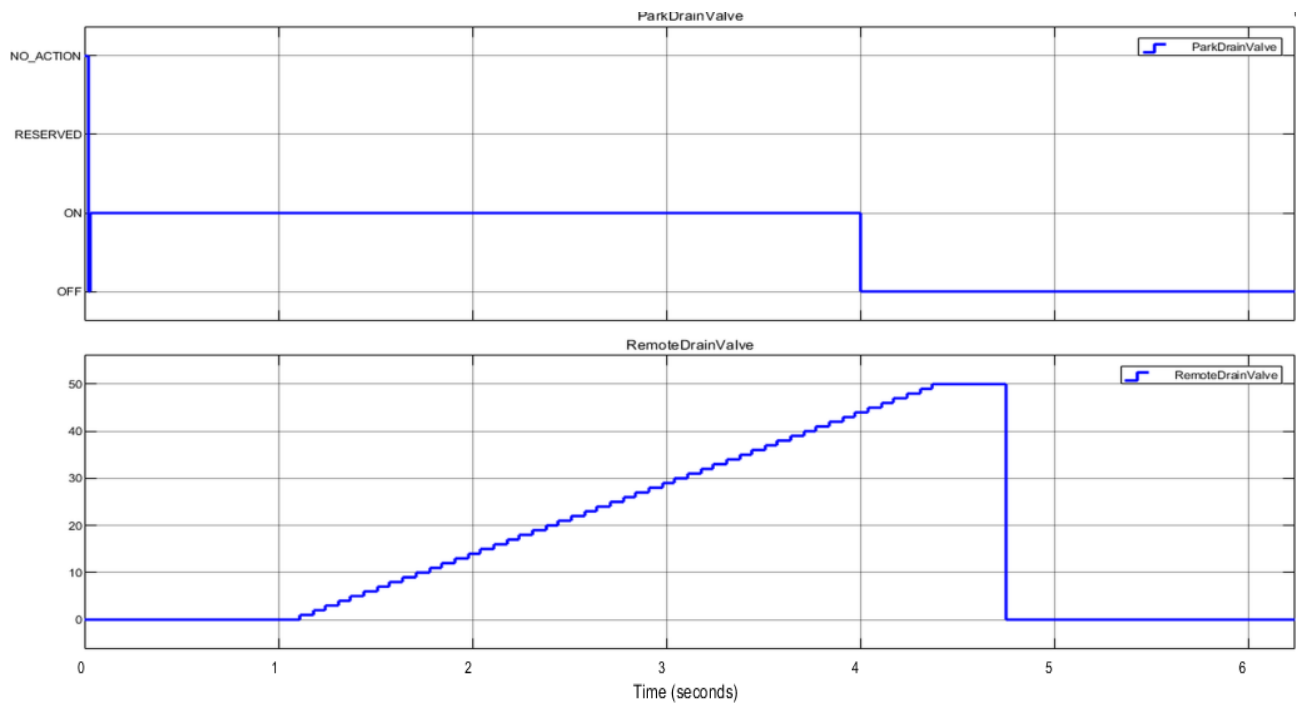

Fig. 8. Graph of parking brake activation, parking and remote circuits brake valve position

At the time of 1 second the parking brake is activated (upper graph). Gradually, the valve controlling the working circuit of the brake system begins to open (lower graph), while the parking circuit valve is closed (middle graph). As the minimum speed is reached (Figure 9), the parking circuit valve is activated and the control system, having verified that the vehicle is stopped, disengages the service brake system mechanisms.

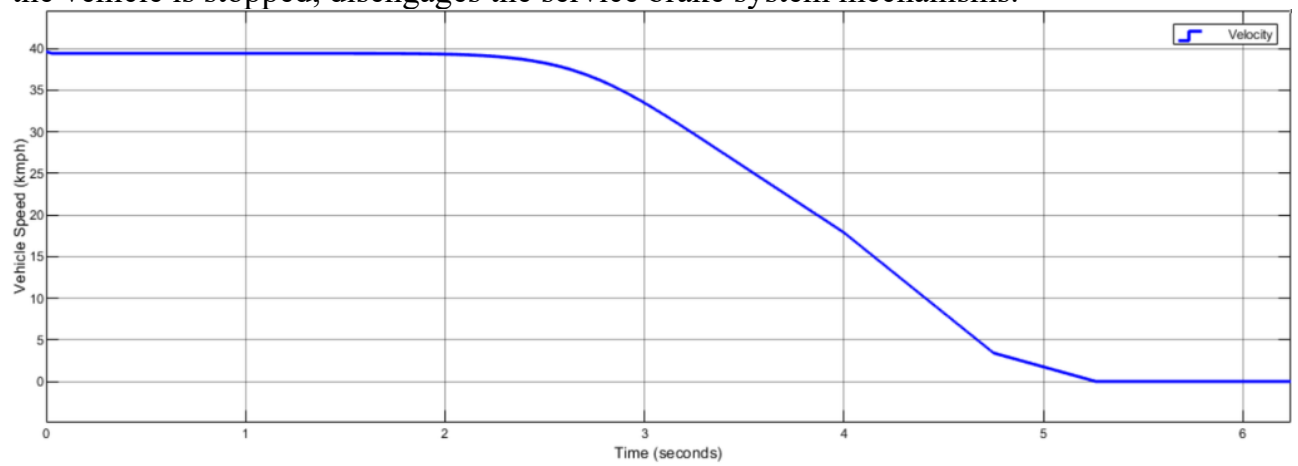

Fig. 9. Diagram of speed change of the wheeled machine

\section{Conclusion}

Within the limits of the lead researches theoretical acknowledgement of working ability of the algorithm of management of a braking system of an autonomous haul truck on an imitational model is executed. The received results reflect the possibility of realization of joint work of two braking systems. Thereby the possibility of overcharge of traction batteries is excluded at movement on prolonged descents at the expense of the control interception realized for the period not exceeding 1 second. Regenerative braking system within the framework of the analysis provided deceleration of the vehicle not exceeding $2.25 \mathrm{~m} / \mathrm{s}^{2}$, which is enough to maintain the necessary speed on slopes and to use as an auxiliary braking system.

The work is financially supported by the Ministry of Science and Higher Education of the 
Russian Federation under the agreement № 075-11-2020-031 dated 14.12.2020 with PJSC KAMAZ on the integrated project "Development of high-tech production of the family of robotized dump trucks with payload capacity up to $90 \mathrm{t}$ with electromechanical transmission based on digital technology", with participation of T.F. Gorbachev Kuzbass State Technical University in terms of research, development and technological works.

\section{References}

1. M. Ehsani, Y. Gao, S. E. Gay, A. Emadi, Modern Electric, Hybrid Electric, Fuel Cell Vehicles (CRC Press, New York, 2005)

2. W. Shabbir, Control Strategies for Series Hybrid Electric Vehicles $(\mathrm{PhD}$ Thesis, Imperial College, London, 2015)

3. F.R. Salmasi, IEEE Transactions on Vehicular Technology 56(5), 2393 (2007)

4. W. Shabbir, S. Evangelou. "Exclusive Operation Strategy for the Supervisory Control of Series Hybrid Electric Vehicles", IEEE Transactions on Control Systems Technology, (2016)

5. C. von Albrichsfeld, J. Karner, SAE Technical Paper 2009-01-1217 (2009)

6. B. Liu, Research and implementation of braking energy recovery system based on pure electric vehicle (Tsinghua University, Beijing, 2004)

7. D. Dubinkin, V. Sadovets, G. Kotiev, A. Kartashov, Journal of mining and geotechnical engineering, 4(7), 50 (2019)

8. D. Dubinkin, V. Aksenov, M. Tyulenev, S. Markov S., Journal of mining and geotechnical engineering, 4(11), 42 (2020)

9. D.M. Dubinkin, Mining Equipment and Electromechanics, 4(150), 59 (2020)

10. D.M. Dubinkin, A.B. Kartashov, G.A. Arutyunyan, N.V. Buzunov, K.P. Sorokin, A.V. Yalyshev, Mining Equipment and Electromechanics, 6(152), 31 (2020)

11. D.M. Dubinkin, Mining equipment and electromechanics, 6(146), 8 (2019)

12. N.V. Buzunov, R.D. Pirozhkov, A.B. Kartashov, D.M. Dubinkin, Bulletin KuzSTU. 6(142), 87 (2020)

13. M.A. Tyulenev, S.O. Markov, D.M. Dubinkin, V.V. Aksenov, Bulletin KuzSTU. 1(143), 97 (2021)

14. A.P. Hu, Research on regenerative braking system based on AMESim-Simulink simulation (Jilin University, Changchun, 2008)

15. P.Y. Wang, Research on regenerative braking system of hybrid cars (Jilin University, Changchun, 2008)

16. L. Yu, Chinese Journal of Mechanical Engineering 43(09), 40 (2007)

17. L. Petruccelli, M. Velardocchia, A. Sorniotti, SAE Technical Paper 2003-01-3336 (2003)

18. A.C. Özdemir, Scientific Mining Journal, 59(4), 247 (2020)

19. H. Sis, T.Karaagac, M. Birinci, T. Kiyak, Scientific Mining Journal, 60(1), 31 (2021)

20. A.E.Dursun, Scientific Mining Journal, 58(4), 299 (2019) 